\title{
Effect of Heat Input on Distortions and Residual Stresses Induced by Gas Tungsten Arc Welding in SS 316L to INCONEL625 Multipass Dissimilar Welded Joints
}

\author{
Harinadh Vemanaboina $\left(\mathbb{D},{ }^{1}\right.$ B Sridhar Babu, ${ }^{2}$ Edison Gundabattini $\left(\mathbb{D},{ }^{3}\right.$ Paolo Ferro $\left(\mathbb{D},{ }^{4}\right.$ \\ and Kaushik Kumar $\left.{ }^{5}\right)^{5}$ \\ ${ }^{1}$ Sri Venkateswara College of Engineering and Technology (Autonomous), Chittoor, Andhra Pradesh, India \\ ${ }^{2}$ CMR Institute of Technology, Hyderabad, Telengana, India \\ ${ }^{3}$ Vellore Institute of Technology, Vellore, Tamilnadu, India \\ ${ }^{4}$ Department of Engineering and Management, University of Padua, Stradella San Nicola 3, 36100 Vicenza, Italy \\ ${ }^{5}$ Birla Institute of Technology, Mesra, Ranchi, India \\ Correspondence should be addressed to Kaushik Kumar; kkumar@bitmesra.ac.in
}

Received 10 October 2021; Revised 29 October 2021; Accepted 6 November 2021; Published 22 November 2021

Academic Editor: Abílio De Jesus

Copyright (C) 2021 Harinadh Vemanaboina et al. This is an open access article distributed under the Creative Commons Attribution License, which permits unrestricted use, distribution, and reproduction in any medium, provided the original work is properly cited.

\begin{abstract}
In the present study, distortion and residual stresses in the multipass welded joint were analyzed with respect to heat input. The welded joint was produced using the gas tungsten arc welding (GTAW) process with dissimilar Ni-based filler of ERNiCrMo-3. This dissimilar joint is essential in power generating nuclear and thermal plants operating at elevated temperatures. The distortion and residual stress measurements were taken using the Vernier height gauge and XRD method. To evaluate the mechanical properties, tensile testing was carried out at room temperature. The welded joint qualified the tensile test with an average value of $593 \mathrm{MPa}$. In the weld metal, a significant variation of residual stresses is measured on the top surface of the weldment along with the thickness with peak magnitude of $145 \mathrm{MPa}$ to $180 \mathrm{MPa}$ at the fusion zone.
\end{abstract}

\section{Introduction}

Dissimilar materials combinations such as stainless steels and nickel-based alloys are extensively used in high temperatures and corrosion-resistant applications such as power plants, chemical industries, aerospace, and nuclear applications. In general, the joining of such alloys is obtained by fusion welding that, for its nature, involves localized heating and cooling in the joining zone of the workpieces; the heat produced during welding leads to metallurgical and structural changes such as distortion and residual stress which shorten (or negatively affect) the life of the welded structure. Kumar and Shahi [1] reported the effect of heat input in microstructure and mechanical properties of weldments made out of AISI 304, $6 \mathrm{~mm}$ thick plates with double $\mathrm{V}$-grooved edge preparation. Three heat inputs have been used for comparison, while the interpass temperature has been maintained equal to about $150^{\circ} \mathrm{C}$. It was found that the lower the heat input, the higher the ultimate tensile strength. Adamczuk et al. [2] studied the angular distortion induced by the solidification of fusion zones (FZs) in multipass weldments; $16 \mathrm{~mm}$ and $19 \mathrm{~mm}$ thick plates were used in the experiments with a variable heat input of $0.06 \mathrm{~kJ} / \mathrm{mm}$ to $2.5 \mathrm{~kJ} / \mathrm{mm}$. Distortions were measured with a linear variable differential transformer technique. An analytical model was developed to predict the welding induced distortion as a function of process parameters. Deng and Murakawa [3] developed a 3-dimensional finite element model to investigate the distortion mechanism arising in $1 \mathrm{~mm}$, but welded joints were produced by the GMAW process using ABAQUS package.

Ramkumar $[4,5]$ reported a structural characterization and mechanical properties of dissimilar multipass welds of stainless steel to INCONEL (AISI316L/IN625 and AISI304/ 
IN625) joints. A single V-groove joint was used for the GTAW process of constant and pulsed mode power with ER2209, ERNiCr-3, and ERNiCrMo-3 as filler rods. Conventional (optical) and advanced (SEM/EDAX) microscopy was carried out to characterize the joints. In both cases, the fracture was always observed to occur at stainless steel parent metal. The detailed study of microstructure and mechanical properties are reported for dissimilar materials in [6-10]; the examination is carried out for stainless steels and nickelbased alloys and its combination using the arc (GTAW and SMAW), friction, and electron beam welding processes. Arc welding processes are carried out with suitable fillers wires of various diameters to improve the joints' structure and strength properties. Laser, electron beam, and friction welding processes are carried out without using filler materials. The effect of the filler wire was also reported for solid solubility with the welds' base material and micro- and mechanical properties. The metallurgical study was reported at various zones of the weldment. The effect of filler metal chemical composition was analyzed. It was found that sound welds, less susceptible to hot cracking, are obtained with the filler metal.

Juang and Tarng [11] were interested in finding process parameters inducing optimal weld pool geometry in stainless steels' TIG welding. To reach that goal, they used $\mathrm{L}_{16}\left(4^{5}\right)$ orthogonal array and the modified Taguchi method. Process parameters' optimization was the focus of Manikandan's research work [12], as well. The design of experiments (DOE) and Taguchi method with $\mathrm{L}_{9}$ orthogonal array are used to find the better penetration depth induced by the pulsed-current gas tungsten arc welding (PCGTAW) process. It was observed that the pulsed current was the most influencing parameter on the penetration depth. Kumar and Sundarrajan [13] investigated the influence of peak and base current, weld torch velocity, and frequency on the structural and mechanical properties of AA5456 aluminium alloy welded joints. They were optimized using the two-level parameters with $\mathrm{L}_{8}$ orthogonal array for the pulsed TIG welding process. They also observed an improvement in mechanical properties due to the planishing effect.

A welding numerical model was developed by Vemanaboina et al. $[14,15]$ to study the temperature distribution during the process and residual stresses in the weldments produced by GTAW [14] and in multipass dissimilar welding (IN625/SS316L) [15]. In this last work, both constant and pulsed current GTAW processes along with ERNiCrMo-3 and ERNiCr-3 filler rods were used. It was observed that residual stresses were lower in the pulsed current GTAW process with ERNiCrMo-3 with a 95\% confidence level. Finally, it was highlighted that the root gap was the most critical parameter. Hashemzadeh et al. [16] reported the variations of residual stresses for $4 \mathrm{~mm}$ and $6 \mathrm{~mm}$ plates joined with single- and multipass welding process, respectively. In their study, temperature distribution and residual stresses were measured on the external surface of the weld. The FE model was developed using the commercial numerical code $\mathrm{ANSYS}^{\circledR}$ and validated with experimental results.
To the best of the authors' knowledge, no research has been carried out on the impact of heat input in multipass dissimilar weldments in the present literature. In this work, the study was focused on understanding the effect of heat input on residual stress and distortion in multipass dissimilar weldments. The joining process was carried out with a gas tungsten arc welding process between SS316L and INCONEL625, using ERNiCrMo-3 filler rod. Distortion and residual stress are measured using the Vernier height gauge and X-ray diffraction technique, respectively.

\section{Materials and Experimental Procedure}

Dissimilar SS316L-INCONEL625 welded joints were obtained using gas tungsten arc welding process using the ERNiCrMo-3 filler wire, suitable for Inconel alloys of various grades. During the process, the $60^{\circ} \mathrm{V}$ groove was filled by the filler metal in three passes. The plates measured $100 \mathrm{~mm} \times 60 \mathrm{~mm} \times 5 \mathrm{~mm}$, while the filler wire diameter was $2.4 \mathrm{~mm}$. The chemical composition of parent materials and filler wire used in this study is collected in Table 1. The thermal conductivity of SS316L and INCONEL 625 is $21.26 \mathrm{~W} / \mathrm{m} \mathrm{K}$ and $16.78 \mathrm{~W} / \mathrm{m} \mathrm{K}$, respectively. The welding parameters' values used in the experiments are summarized in Table 2. The root gap was about $2.0 \mathrm{~mm}$ (Table 2), while the voltage was maintained at a constant value of 12 volt for all the trials. The interpass temperature was about $200-250^{\circ} \mathrm{C}$ $[15,17]$ to avoid hot cracking during the welding process.

2.1. Heat Input. The heat input is quantified by Equation (1) [15], where $I$ is the current (ampere), $\mathrm{V}$ is the voltage (volts), and $S$ is the welding speed $(\mathrm{mm} / \mathrm{min})$. The heat input is increased according to the changes in the process parameters used (Table 2). The heat input is calculated for each pass and the average heat input used in each trial is reported in Figure 1:

$$
H_{i}=\left(\frac{I^{*} V^{*} 0.06}{S}\right) \text {. }
$$

2.2. Distortion. Any unwanted geometrical change or departure from specifications in a fabricated structure or component, as a consequence of welding, is called welding distortion. Nonuniform expansion and contraction of the weld metal and the surrounding base metal create weld distortion during the welding process, which occurs throughout the heating and cooling cycles. In a dissimilar weld, there is also an effect induced by both the nonuniform heat flux resulting from different values of alloys thermal conductivity and different thermal expansions coefficients of the coupled alloys. The calculation of the weldment's angular distortion [17-20], expressed in degrees, is carried with

$$
\alpha=\sin ^{-1}\left[\frac{h_{1}-h_{2}}{b}\right],
$$

where $h_{1}$ is the total height at Vernier height, $h_{2}$ is the total height of the workpiece from the surface, and $b$ is the length of the plate. Figure 2(a) shows the types of distortion caused 
TABle 1: Parent materials and filler wire chemical composition.

\begin{tabular}{lccccccccc}
\hline & & \multicolumn{7}{c}{ Element (wt\%) } \\
& $\mathrm{Ni}$ & $\mathrm{C}$ & $\mathrm{Mn}$ & $\mathrm{S}$ & $\mathrm{Cu}$ & $\mathrm{Si}$ & $\mathrm{Cr}$ & $\mathrm{P}$ & Others \\
\hline INCONEL 625 & 58 & 0.1 & 0.5 & 0.015 & 0.5 & 0.5 & $20-23$ & 0.015 & $\mathrm{Fe} \mathrm{5,} \mathrm{Al} \mathrm{0.40,} \mathrm{Mo} \mathrm{8-10,} \mathrm{Ti} \mathrm{0.1}$ \\
SS 316L & $12-18$ & 0.03 & 2.00 & 0.030 & - & 1.00 & $16-18$ & 0.045 & Mo 2-3 \\
ErNiCrMo-3 & 64 & 0.1 & 0.5 & 0.015 & 0.50 & 0.50 & $22-23$ & 0.015 & $\mathrm{Fe} \mathrm{1.0,} \mathrm{Al} \mathrm{0.40,} \mathrm{Nb} \mathrm{3.6-4.5,} \mathrm{Mo} \mathrm{0.015,} \mathrm{Ti} \mathrm{0.40}$ \\
\hline
\end{tabular}

Table 2: Process parameters and their levels.

\begin{tabular}{|c|c|c|c|c|}
\hline Process parameters/trial no/units & $\begin{array}{c}\text { Welding current } \\
\text { Amp }\end{array}$ & $\begin{array}{c}\text { Argon flow rate } \\
\text { LPM }\end{array}$ & $\begin{array}{c}\text { Welding speed } \\
\mathrm{mm} / \mathrm{min}\end{array}$ & $\begin{array}{c}\text { Root gap } \\
\mathrm{mm}\end{array}$ \\
\hline 1 & 135 & 12 & 125 & 2.0 \\
\hline 2 & 145 & 12 & 113 & 2.0 \\
\hline 3 & 155 & 12 & 129 & 2.0 \\
\hline
\end{tabular}

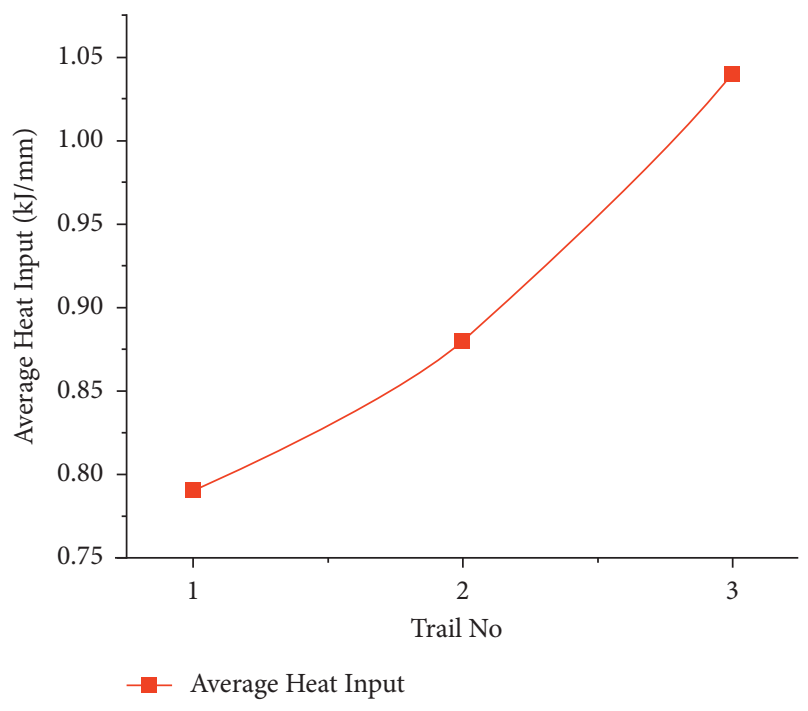

FIgURE 1: Heat input for various trials.

by welding in both the longitudinal and transverse direction of weldments, arising as soon as they are unclamped. The distortion measurement principle using the Vernier height gauge in butt-welded joints is shown in Figure 2.

2.3. Residual Stress. In this work, RS is measured in a transverse direction (perpendicular to the weld line) at various distances from the weld line on both the top and bottom surfaces of the weldment. Before measuring, the sample surface was cleaned with emery sheets. The arc welding process is linked to the underlying local heating and cooling cycles. The combined effects of thermal stress and strain would leave the welds with residual stresses. The measurement of residual stresses is carried out using the $\mathrm{X}$-ray diffraction method as

$$
n \lambda=2 d \sin \theta
$$

where $n$ refers to the order of the reflected beam, $d$ is the interplanar lattice spacing, $\lambda$ the wavelength of the incident wave, and $\theta$ is the scattering angle. Residual stress was calculated on the upper surface of the weld in the transverse direction by using the following equation:

$$
\sigma_{\phi}=\frac{m}{d_{0}}\left(\frac{E}{1+v}\right)
$$

Young's modulus is $E, v$ is the Poisson coefficient, and $d_{0}$ is the stress-free lattice spacing. Figure 3 shows the equipment used in the present work for measuring welding residual stress. Bragg's angle of $155^{\circ}$ and the wavelength of $2.103[\AA]$ were used for the measurements. The measuring parameters are given in Table 3.

\section{Results and Discussion}

3.1. Nondestructive Tests for Weld Quality Analysis. The radiographic test is a nondestructive technique used for detecting defects such as flaws, cracks, or porosity in the weldment. The test piece is placed between the X-ray source and the film throughout the imaging process (or detector). Variations in the density and thickness of the test material will reduce the penetrating radiation's intensity via interaction processes such as scattering and/or absorption. It is possible to capture the variations in absorption on film or electronically. ASME SEC IX-2017 standard was used for the quality testing of the weldments. It was observed that all weldments had straight white lines indicating acceptable weldments. The obtained results, shown in Figure 4, confirmed the soundness of the welds under investigation; the weldments were free from defects.

3.2. Distortion. Temperature gradients induced by welding cause dimensional changes in the weldments that adversely affect the structure assembly. The weld distortions were measured after the last welding pass and the joints reached the ambient temperature. Heating and cooling cycles during multipass welding cause local nonhomogeneous plastic deformation that result in distortion of the weld parts at the macroscale. This change will affect the design of critical parts such as turbine blades, heat exchangers, and pressurizer surge nozzles that need to fit during the assembly operations exactly. Lower the quality characteristics chosen for the weld distortion is, better the characteristics is. The lowest was observed in trail1 with $0.72^{\circ}$ at $0.79 \mathrm{~kJ} / \mathrm{mm}$, in trail-2 with $1.2^{\circ}$ at $0.88 \mathrm{~kJ} / \mathrm{mm}$, and in trail-3 with $1.43^{\circ}$ with a heat input of $1.04 \mathrm{~kJ} / \mathrm{mm}$. With 


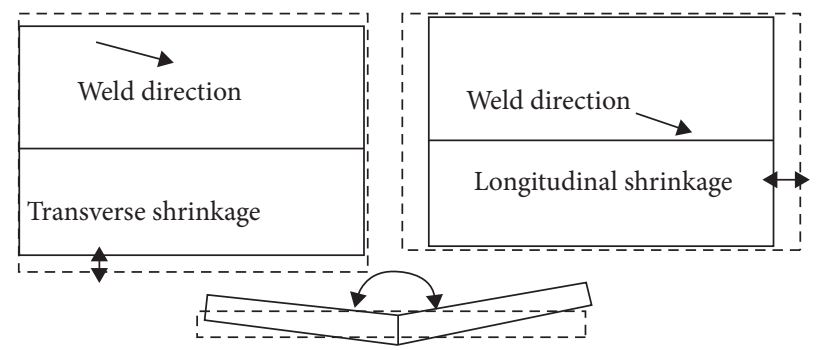

(a)

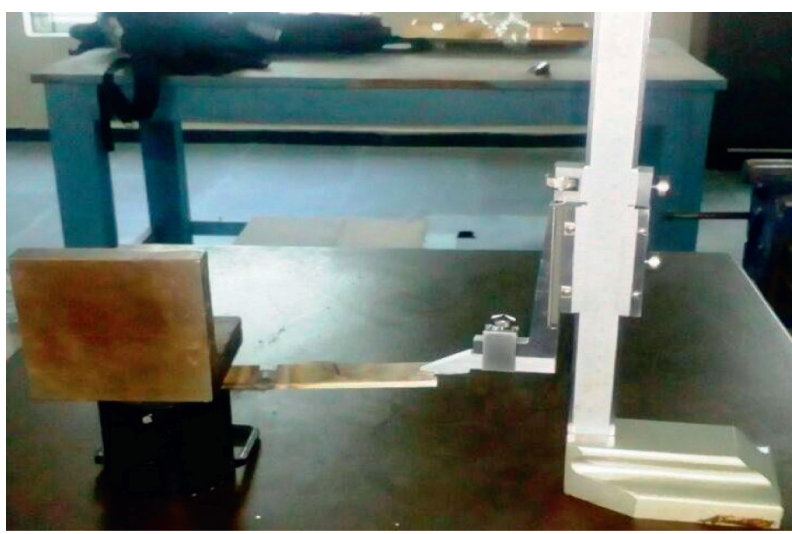

(b)

FIgURE 2: (a) Different types of weld distortions and shrinkages. (b) Measurement of weld distortion using Vernier height gauge.

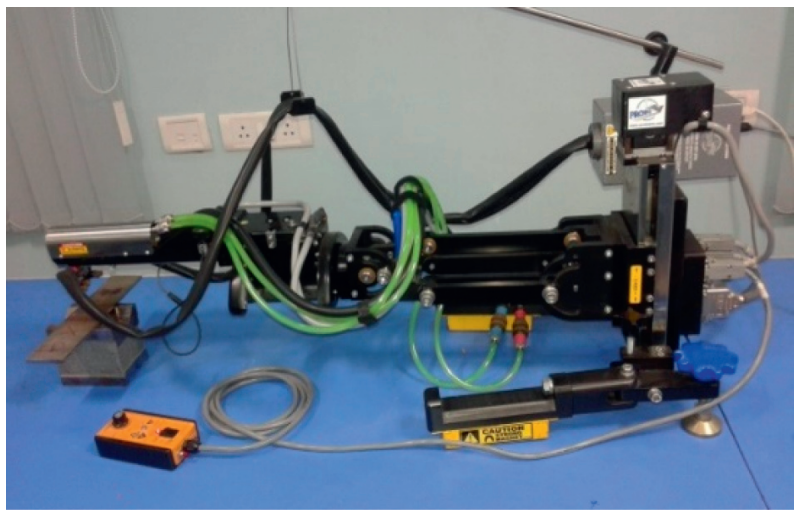

(a)

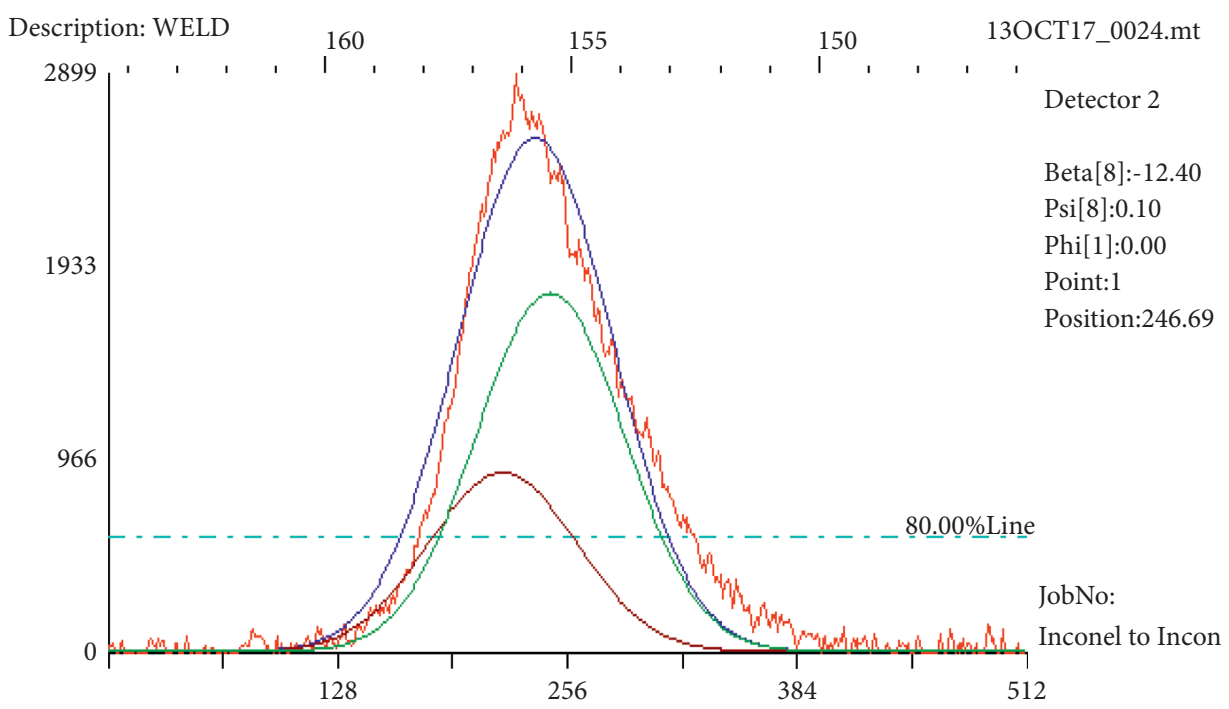

(b)

FIGURE 3: Residual stress measuring instrument.

the increase of $0.09 \mathrm{~kJ} / \mathrm{mm}$ heat input, the distortion in the weldment raised to $0.48^{\circ}$ which was found in trail-1 to trail- 2 . In trail-2 to trail-3, it was about $0.16 \mathrm{~kJ} / \mathrm{mm}$ difference in heat input, but the distortion was raised to $0.23^{\circ}$. In all the joints, distortion was lower at the Inconel side than the stainless steel side; this is due to higher thermal conductivity and lower thermal expansion coefficient of the SS alloy [18]. The weld distortion increases with the increase of the total heat input (Figure 5). However, its value resulted always below $2^{\circ}$, which is the recommended limit to assure the assembly [19]. 
TABLE 3: Tensile strength properties of dissimilar weldments of INCONEL625 and SS3161.

\begin{tabular}{|c|c|c|c|c|}
\hline Property & Units & Trial-1 & Trial-2 & Trial-3 \\
\hline Maximum load & $\mathrm{kN}$ & 36.72 & 36.52 & 36.04 \\
\hline Ultimate tensile strength & $\mathrm{MPa}$ & 594.65 & 595.75 & 590.72 \\
\hline $0.2 \%$ proof strength & $\mathrm{MPa}$ & 340.80 & 344.31 & 360.07 \\
\hline Elongation & $\%$ & 31.04 & 33.20 & 32.20 \\
\hline Fracture zone & - & & Fracture at SS side & \\
\hline
\end{tabular}

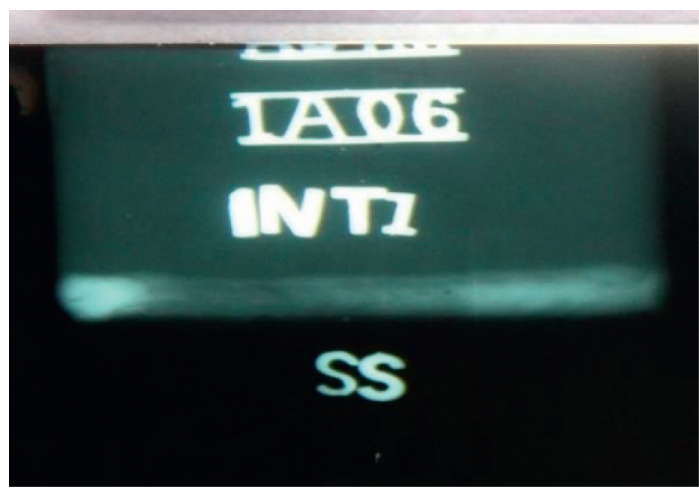

(a)

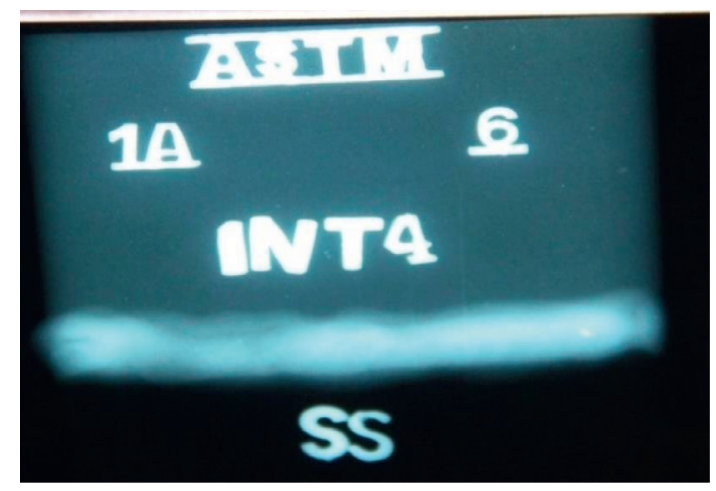

(b)

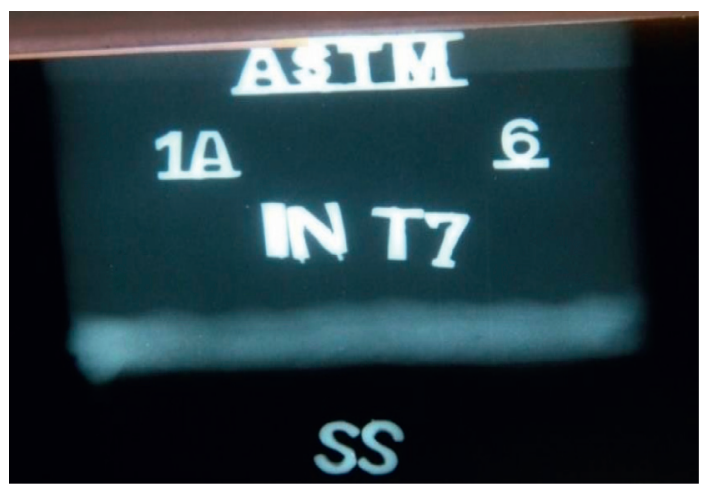

(c)

Figure 4: Radiography test of the weldments.

3.3. Residual Stresses. It is one of the most commonly used destructive methods for the measurement of the residual stresses. The stress measurement was carried out at the fusion zone for all the trials after completing the third pass and cooling to ambient temperature. The peak longitudinal and transverse residual stress magnitude was at the weld zone. Tensile residual stresses were found throughout the plate with peak magnitude of the longitudinal stress which was the top surface of the weld plate at the fusion zone. The observed residual stress value for tail- 1 is $145 \mathrm{MPa}$, trail-2 is $158 \mathrm{MPa}$, and trail-3 is $180 \mathrm{MPa}$. The measured value on the welded joints was obtained with the heat input equal to $0.79 \mathrm{~kJ} / \mathrm{mm}, 0.88 \mathrm{~kJ} / \mathrm{mm}$, and $1.04 \mathrm{~kJ} / \mathrm{mm}$, respectively. Tensile stresses were observed in the fusion zone. The increasing trend with heat input is shown in Figure 6. Even though the thermal conductivity of the SS316L is 1.3 times greater than that of the Inconel material, the residual stresses show a better factor of safety at the joint when compared to yield strength of parent materials. Thermal and mechanical properties such as thermal conductivity, the coefficient of thermal expansion, and the yield strength of the base materials will play a vital role in residual stresses distribution in the dissimilar joints. The joint obtained in trial-1 is characterized by a factor of safety of the base material equal to 1.58 , second one by a value of 1.45 , and the last by a value of 1.27 . The almost linear increase of the residual stresses with the heat input (Figure 6) induces a decrease of the safety factor, which suggests a life reduction of the joint. With the increase of $0.09 \mathrm{~kJ} /$ $\mathrm{mm}$ heat input, the stresses in increasing trend of $9 \mathrm{MPa}$ were found in trail-1 to trail-2. Whereas from trail-2 to trail-3, it was about $0.16 \mathrm{~kJ} / \mathrm{mm}$ difference in heat input, but the residual stresses are increased in tensile of about $22 \mathrm{MPa}$ [21-24]. Based on authors' experience, in order to minimize the increasing linear trend of welding residual stresses, it is recommended that first pass be carried out with a higher weld current compared to that used for the remaining passes.

3.4. Weld Bead Geometry. Weld bead shapes are shown in Figure 6. A good aspect ratio was observed for all the weldments. The bead geometry was measured at a vertical and 


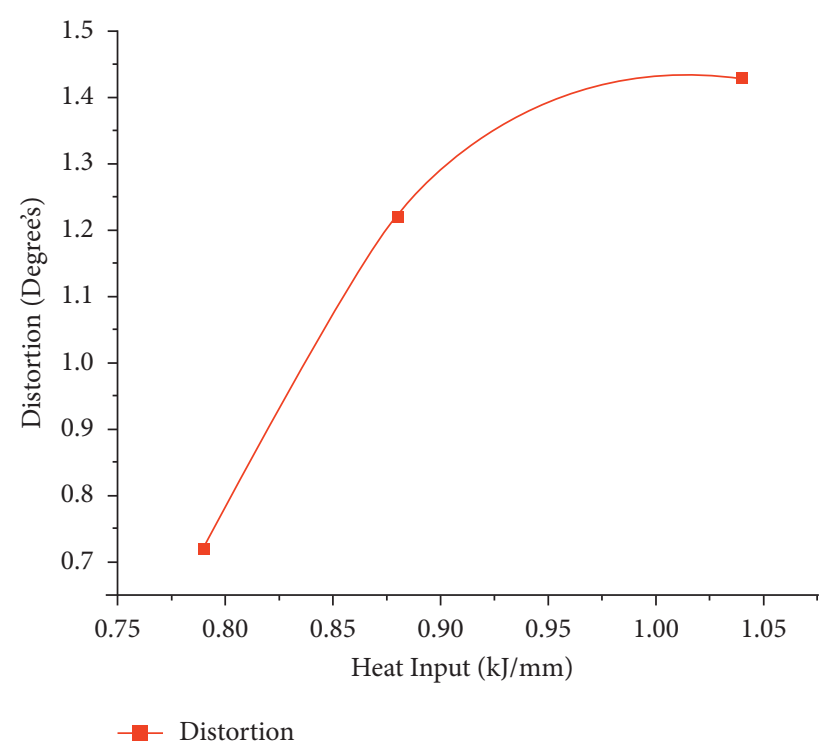

FIgURE 5: Weld distortion as a function of total heat input.

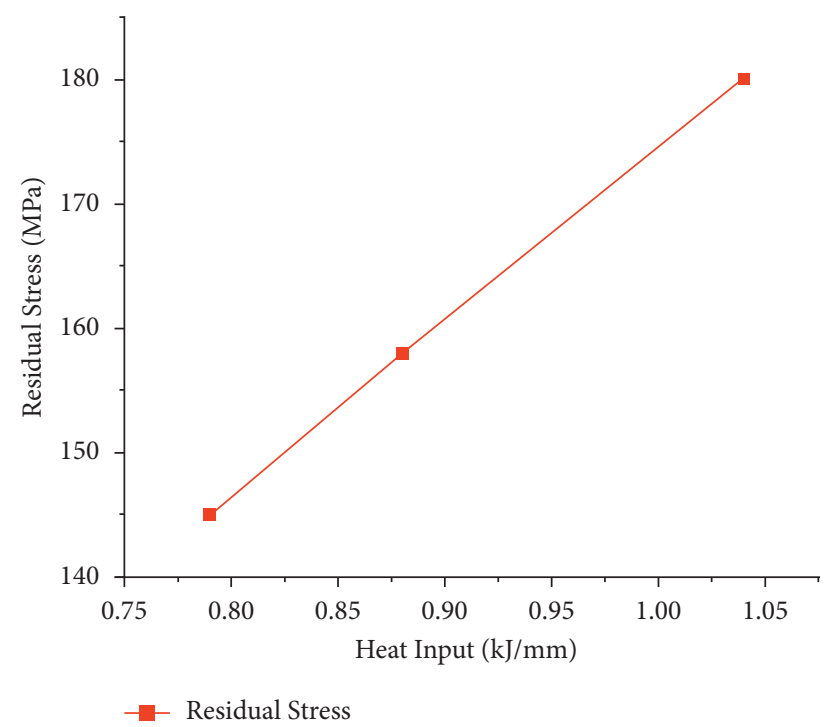

FIgURE 6: Residual stresses as a function of heat input.

horizontal position at the fusion zone. In Figure 7(a), for Trial1 , the root pass width is $8.42 \mathrm{~mm}$, the filler pass width is $6.58 \mathrm{~mm}$, and the final bead height is $7.37 \mathrm{~mm}$ with a total bead width of $9.98 \mathrm{~mm}$. In Figure 7(b), for Trial-2, at the weld root, the width is $7.37 \mathrm{~mm}$, at the midpass, the bead width is $6.11 \mathrm{~mm}$, and, at the cap pass, the total width is $12.10 \mathrm{~mm}$ with a total bead height of $6.53 \mathrm{~mm}$. Finally, in Figure 7(c), for trial3 , the root pass width is $10.82 \mathrm{~mm}$, at the midpass, width is $6.03 \mathrm{~mm}$, while, at the cap pass, it is $9.80 \mathrm{~mm}$ with a total FZ height of $7.30 \mathrm{~mm}$. In Figure 7(c), the excess of penetration observed compared to the other two trials is due to the higher welding current used. It was observed that a uniform distribution of filler metal characterizes all welded joints.

3.5. Tensile Strength. The multipass dissimilar welds of $5 \mathrm{~mm}$ thick plates were tested for tensile properties. The tensile testing was carried out for all specimens in the transverse direction (across the welds) as per the ASTM A 370:2012. Plastic deformation was observed before samples' fracture. All the multipass dissimilar welds failed at parent material, stainless steel (SS) side (Figure 8). The average tensile strength and $0.2 \%$ 


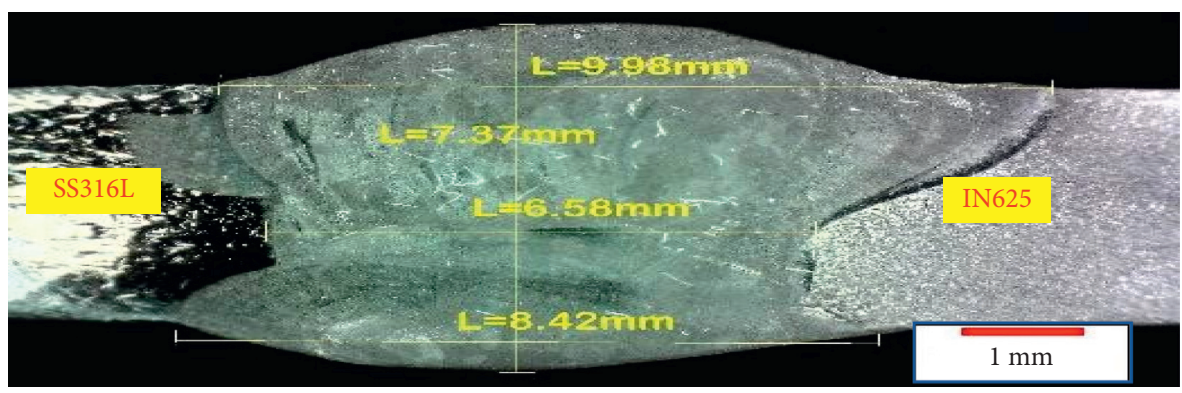

(a)

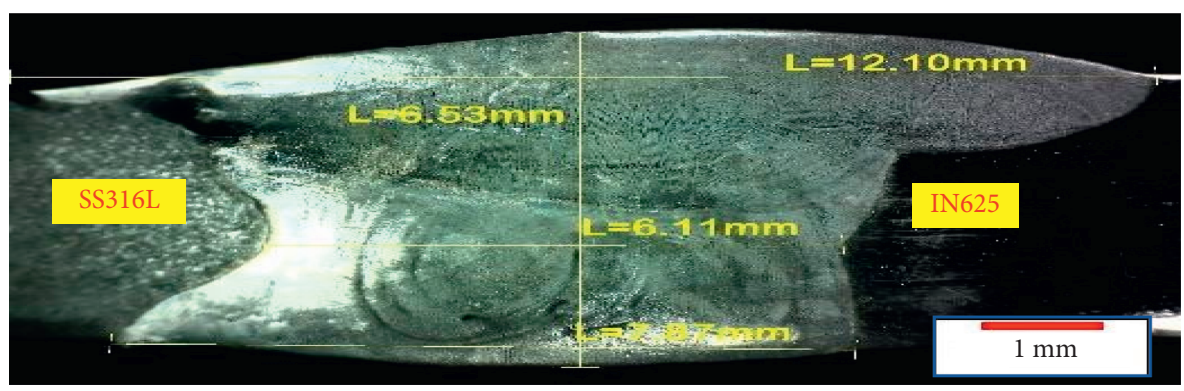

(b)

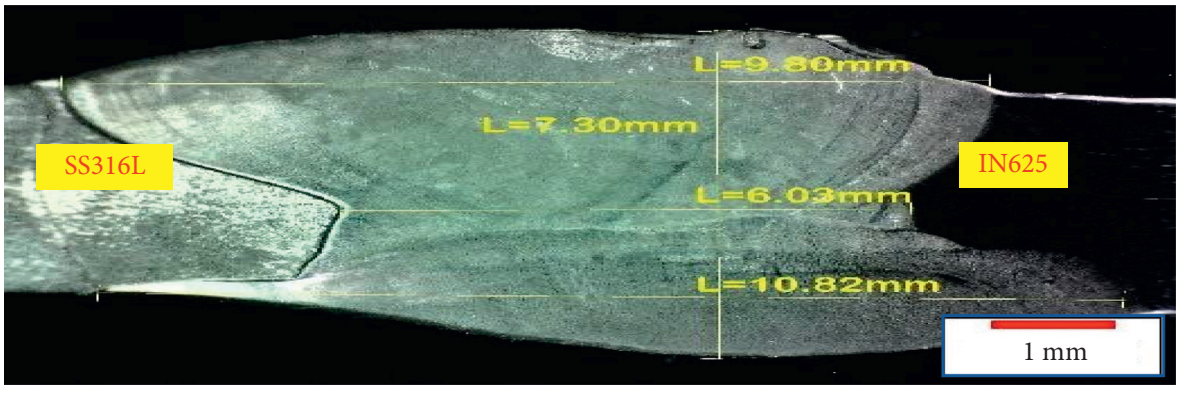

(c)

Figure 7: Weld bead geometry: (a) trial-1, (b) trial-2, and (c) trial-3.

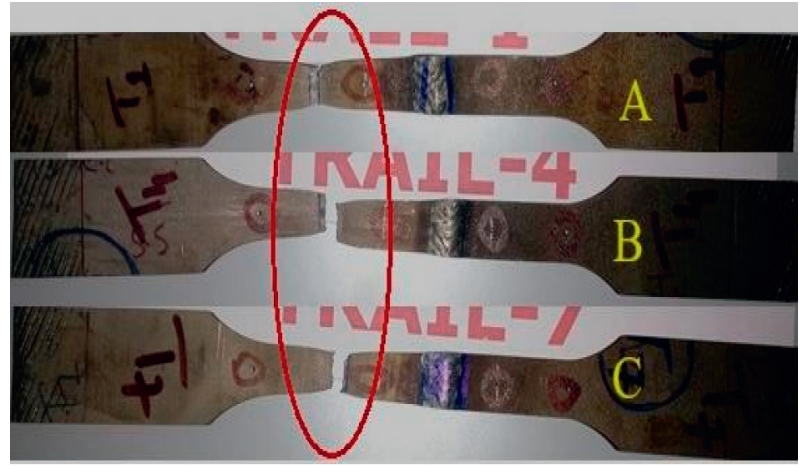

(a)

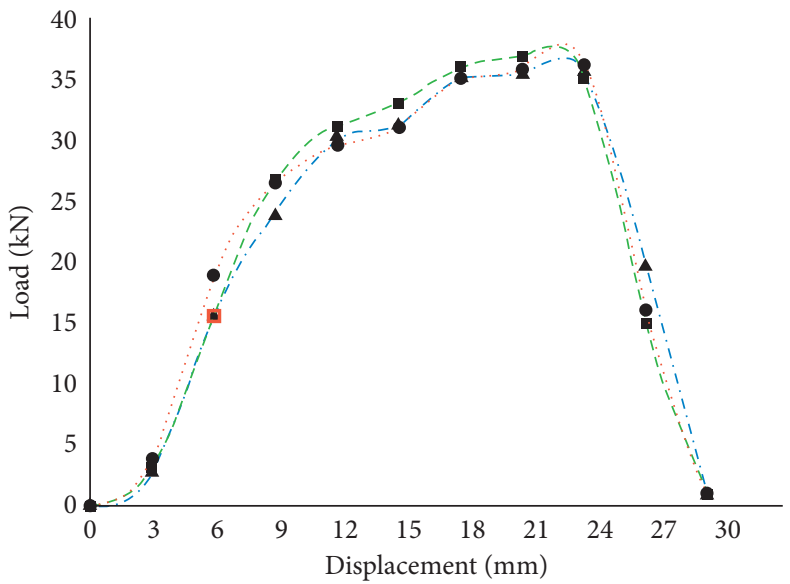

Trail-1

Trail-2

Trail-3

(b)

FIgURE 8: Specimens after machining prepared for tensile strength. (a) Fracture occurred at the parent metal of SS316L. (b) Load vs. displacement. 
proof strength were found to be $593 \mathrm{MPa}$ and $348.4 \mathrm{MPa}$, as reported in Table 3. Compared with the base materials, all the weldments showed higher tensile strength.

\section{Conclusions}

Dissimilar welding between Inconel 625 and stainless steel 316L was carried out using the GTAW process with various heat inputs. All the weldments were verified to be free from cracks and flaws via radiography tests. The distortion and residual stresses were found to vary with heat input. The main results can be summarized as follows:

(i) With the incorporation of interpass temperatures between the second and third pass, the hot cracking defects had overcome

(ii) The peak magnitude of the longitudinal stress and transverse stress was measured with a minimum of $145 \mathrm{MPa}$ and maximum of $180 \mathrm{MPa}$, respectively, under the weld condition

(iii) The average tensile strength was measured $593 \mathrm{MPa}$ for with joint efficiency of higher than 100\%

(iv) The heat input increased, resulting in higher distortion and tensile residual stresses in weldments

(v) The peak magnitude of the longitudinal stress and transverse stress was measured $145 \mathrm{MPa}$ to $180 \mathrm{MPa}$, respectively, in the weldment

(vi) Furthermore, to decrease the distortion and residual stresses peaks, authors recommend welding with high heat input for the first pass for proper mixing of base and filler materials, and further, there are decreases in heat input for second and third passes by maintaining interpass temperatures

\section{Data Availability}

The data used to support the findings of the study are available within the article.

\section{Conflicts of Interest}

The authors declare that they have no conflicts of interest.

\section{References}

[1] S. Kumar and A. S. Shahi, "Effect of heat input on the microstructure and mechanical properties of gas tungsten arc welded AISI 304 stainless steel joints," Materials \& Design, vol. 32, no. 6, pp. 3617-3623, 2011.

[2] P. C. Adamczuk, I. G. Machado, and J. A. E. Mazzaferro, "Methodology for predicting the angular distortion in multipass butt-joint welding," Journal of Materials Processing Technology, vol. 240, pp. 305-313, 2017.

[3] D. Deng and H. Murakawa, "Prediction of welding residual stress in multi-pass butt-welded modified 9Cr-1Mo steel pipe considering phase transformation effects," Computational Materials Science, vol. 37, no. 3, pp. 209-219, 2006.

[4] K. G. Kumar, K. D. Ramkumar, and N. Arivazhagan, "Characterization of metallurgical and mechanical properties on the multi-pass welding of Inconel 625 and AISI 316L,"
Journal of Mechanical Science and Technology, vol. 29, no. 3, pp. 1039-1047, 2015.

[5] K. D. Ramkumar, P. Mithilesh, D. Varun et al., "Characterization of microstructure and mechanical properties of Inconel 625 and AISI 304 dissimilar weldments," ISIJ International, vol. 54, no. 4, pp. 900-908, 2014.

[6] H. Naffakh, M. Shamanian, and F. Ashrafizadeh, "Weldability in dissimilar welds between type 310 austenitic stainless steel and Alloy 657," Journal of Materials Science, vol. 43, no. 15, pp. 5300-5304, 2008.

[7] H. Naffakh, M. Shamanian, and F. Ashrafizadeh, "Microstructural evolutions in dissimilar welds between AISI 310 austenitic stainless steel and Inconel 657," Journal of Materials Science, vol. 29, no. 45, pp. 2564-2573, 2010.

[8] N. Arivazhagan, S. Singh, S. Prakash, and G. M. Reddy, "Investigation on AISI 304 austenitic stainless steel to AISI 4140 low alloy steel dissimilar joints by gas tungsten arc, electron beam and friction welding," Materials \& Design, vol. 32, no. 5, pp. 3036-3050, 2011.

[9] R. Dehmolaei, M. Shamanian, and A. Kermanpur, "Microstructural characterization of dissimilar welds between alloy 800 and HP heat-resistant steel," Materials Characterization, vol. 59, no. 10, pp. 1447-1454, 2008.

[10] I. Hajiannia, M. Shamanian, and M. Kasiri, "Microstructure and mechanical properties of AISI 347 stainless steel/A335 low alloy steel dissimilar joint produced by gas tungsten arc welding," Materials \& Design, vol. 50, pp. 566-573, 2013.

[11] S. C. Juang and Y. S. Tarng, "Process parameter selection for optimizing the weld pool geometry in the tungsten inert gas welding of stainless steel," Journal of Materials Processing Technology, vol. 122, no. 1, pp. 33-37, 2002.

[12] M. Manikandan, M. N. Rao, R. Ramanujam, D. Ramkumar, N. Arivazhagan, and G. M. Reddy, "Optimization of the pulsed current gas Tungsten Arc welding process parameters for alloy C-276 using the Taguchi method," Procedia Engineering, vol. 97, pp. 767-774, 2014.

[13] A. Kumar and S. Sundarrajan, "Optimization of pulsed TIG welding process parameters on mechanical properties of AA 5456 Aluminum alloy weldments," Materials \& Design, vol. 30, no. 4, pp. 1288-1297, 2009.

[14] H. Vemanaboina, G. Edison, and S. Akella, "Evaluation of residual stresses in multipass dissimilar butt-welded of SS316L to Inconel625 using FEA," International Journal of Engineering \& Technology, vol. 7, no. 3, p. 1145, 2018.

[15] H. Vemanaboina, G. Edison, and S. Akella, "Effect of residual stresses of GTA welding for dissimilar materials," Materials Research, vol. 21, pp. 1-7, 2018.

[16] M. Hashemzadeh, B.-Q. Chen, and C. Guedes Soares, "Evaluation of multi-pass welding-induced residual stress using numerical and experimental approaches," Ships and Offshore Structures, vol. 31, no. 13, pp. 847-856, 2018.

[17] R. S. Parmar, Welding Engineering and Technology, Khanna Publishers, Delhi, India, 2nd edition, 2010.

[18] H. Vemanaboina, G. Edison, and S. Akella, "Weld bead temperature and residual stresses evaluations in multipass dissimilar INCONEL625 and SS316L by GTAW using IR thermography and x-ray diffraction techniques," Materials Research Express, vol. 6, no. 9, Article ID 0965a9, 2019.

[19] H. Vemanaboina, G. Edison, and S. Akella, "Distortion control in multi pass dissimilar GTAW process using Taguchi ANOVA analysis," International Journal of Engineering and Technologies, vol. 23, no. 7, pp. 1140-1147, 2018.

[20] V. Harinadh, G. Edison, K. Kumar, P. Ferro, and B. Sridhar Babu, "Thermal and residual stress distributions in Inconel 
625 butt-welded plates: simulation and experimental validation," Advances in Materials Science and Engineering, vol. 2021, Article ID 3948129, 12 pages, 2021.

[21] H. Vemanaboina, S. Akella, A. Uma Maheshwer Rao, E. Gundabattini, and R. K. Buddu, "Analysis of thermal stresses and its effect in the multipass welding process of SS316L," Proceedings of the Institution of Mechanical Engineers-Part E: Journal of Process Mechanical Engineering, vol. 235, no. 2, pp. 384-391, 2020.

[22] P. Ferro and N. Petrone, "Asymptotic thermal and residual stress distributions due to transient thermal loads," Fatigue and Fracture of Engineering Materials and Structures, vol. 32, no. 11, pp. 936-948, 2009.

[23] P. Ferro, "Influence of phase transformations on the asymptotic residual stress distribution arising near a sharp V-notch tip," Modelling and Simulation in Materials Science and Engineering, vol. 20, no. 8, Article ID 085003, 2012.

[24] L. Romanin, P. Ferro, F. Bonollo, and F. Berto, "A numerical and experimental analysis of Inconel 625 electron-beam welding-thermal aspects," Procedia Structural Integrity, vol. 18, pp. 63-74, 2019. 